\title{
Quantitative evaluation of emission controls on primary and secondary organic aerosol sources during Beijing 2008 Olympics
}

\author{
S. Guo ${ }^{1,2}$, M. Hu ${ }^{1}$, Q. Guo ${ }^{1}$, X. Zhang ${ }^{1}$, J. J. Schauer ${ }^{3}$, and R. Zhang ${ }^{1,2}$ \\ ${ }^{1}$ State Key Joint Laboratory of Environmental Simulation and Pollution Control, College of Environmental Sciences and \\ Engineering, Peking University, Beijing, 100871, China \\ ${ }^{2}$ Department of Atmospheric Science, Texas A\&M University, College Station, TX 77843, USA \\ ${ }^{3}$ Environmental Chemistry and Technology Program, Wisconsin State Laboratory of Hygiene, University of \\ Wisconsin-Madison, Madison, WI 53706, USA
}

Correspondence to: M. Hu (minhu@pku.edu.cn)

Received: 13 November 2012 - Published in Atmos. Chem. Phys. Discuss.: 19 December 2012

Revised: 2 July 2013 - Accepted: 11 July 2013 - Published: 22 August 2013

\begin{abstract}
To assess the primary and secondary sources of fine organic aerosols after the aggressive implementation of air pollution controls during the 2008 Beijing Olympic Games, $12 \mathrm{~h} \mathrm{PM}_{2.5}$ values were measured at an urban site at Peking University (PKU) and an upwind rural site at Yufa during the CAREBEIJING-2008 (Campaigns of Air quality REsearch in BEIJING and surrounding region) summer field campaign. The average $\mathrm{PM}_{2.5}$ concentrations were $72.5 \pm 43.6 \mu \mathrm{g} \mathrm{m}^{-3}$ and $64.3 \pm 36.2 \mu \mathrm{g} \mathrm{m}^{-3}$ (average \pm standard deviation, below as the same) at PKU and Yufa, respectively, showing the lowest concentrations in recent years. Combining the results from a CMB (chemical mass balance) model and secondary organic aerosol (SOA) tracer-yield model, five primary and four secondary fine organic aerosol sources were compared with the results from previous studies in Beijing. The relative contribution of mobile sources to $\mathrm{PM}_{2.5}$ concentrations was increased in 2008, with diesel engines contributing $16.2 \pm 5.9 \%$ and $14.5 \pm 4.1 \%$ and gasoline vehicles contributing $10.3 \pm 8.7 \%$ and $7.9 \pm 6.2 \%$ to organic carbon (OC) at PKU and Yufa, respectively. Due to the implementation of emission controls, the absolute OC concentrations from primary sources were reduced during the Olympics, and the contributions from secondary formation of $\mathrm{OC}$ represented a larger relative source of fine organic aerosols. Compared with the non-controlled period prior to the Olympics, primary vehicle contributions were reduced by $30 \%$ at the urban site and $24 \%$ at the rural site. The reductions in coal combustion contributions were $57 \%$ at PKU and $7 \%$ at Yufa. Our results demonstrate that
\end{abstract}

the emission control measures implemented in 2008 significantly alleviated the primary organic particle pollution in and around Beijing. However, additional studies are needed to provide a more comprehensive assessment of the emission control effectiveness on SOA formation.

\section{Introduction}

With rapid economic development and increasing energy consumption, Beijing has experienced severe air pollution and has become one of the hotspots for air pollution in the world (Shao et al., 2006). It has been reported that ambient particles, especially fine mode particles, are the most important air pollutant in Beijing (Guo et al., 2010; Hu and Guo, 2009; Chan and Yao, 2008). A comprehensive understanding of the fine mode aerosol sources is important to regulatory agencies for development of effective control policies.

There have been several source apportionment studies in Beijing utilizing a variety of methods during the last few years. Elemental tracers were previously applied to apportion particulate matter (PM) sources (Song et al., 2006a, 2007; Sun et al., 2006). However, the elemental tracer method cannot characterize several important sources that emit mainly organic matters rather than elemental compounds (e.g., cooking and diesel/gasoline engine exhaust). Sun et al. (2012) used radiocarbon $\left({ }^{14} \mathrm{C}\right)$ analysis to determine the sources of carbonaceous aerosol. However, radiocarbon analysis can 
only distinguish fossil fuel carbon from contemporary carbon.

Particulate organic matter (POM) accounted for a large fraction of the fine mode particles $\left(\mathrm{PM}_{2.5}\right)$ (Kanakidou et al., 2005). For instance, in Beijing $30 \%$ to $50 \%$ of the $\mathrm{PM}_{2.5}$ was organic compound mass (Lin et al., 2009). To better identify and quantify the key sources of organic particulate matter, organic molecular tracers have been successfully used in source apportionment models (Schauer et al., 1996; Stone et al., 2009; Guo et al., 2012). Organic tracers have been utilized in several fine particle source apportionment studies in Beijing (Zheng et al., 2005; Wang et al., 2009). Zheng et al. (2005) and Wang et al. (2009) quantified the source contributions to fine mode particles in the years of 2000 and 2005 to 2007 , respectively, using a molecular marker chemical mass balance (CMB) model. However, the particle sources have changed significantly in recent years due to the changes of energy structures and industrial facilities and new air quality control policies.

As the host of the 2008 Olympics, the city of Beijing drew increased attention to its severe fine particle pollution. A series of control measures were implemented by the Beijing Municipal Government in an attempt to reduce $\mathrm{PM}_{2.5}$. Guo et al. (2012) investigated the major particle sources in Beijing during 2008, improving the understanding of secondary organic aerosol (SOA) formation in Beijing. However, it is also important to compare the particle source contributions with previous studies to explore the changes of primary particle emissions in recent years.

It is essential to evaluate the effectiveness of these control measures to advance the scientific perspectives as well as future control strategy developments. Satellite observations and modeling studies have indicated significant particle pollution reduction during the Olympic period (Cermak and Knutti, 2009; Wang et al., 2010c). Huang et al. (2010) presented the observations of the high time-resolved particulate matter chemical compositions, which were measured using an Aerodyne high-resolution time-of-flight aerosol mass spectrometer (HR-ToF-AMS). This study demonstrated that all major particulate matter components have reduced concentrations due to the implemented control measures and favorable weather conditions during the Olympics. However, it is difficult to quantify whether the reductions were associated with emission control or meteorological conditions. Liu et al. (2012) employed a statistical model to evaluate the effects of $\mathrm{PM}_{2.5}$ emission controls, and the results showed only the integrated effects of all control measures but not the specific sources. Source apportionment is a direct and more effective way to evaluate the emission control effects on specific sources quantitatively.

In the present study, $\mathrm{PM}_{2.5}$ values were collected at an urban site and an upwind rural site in Beijing before, during, and after the Olympic Games in 2008. Gas chromatography/mass spectrometry (GC-MS) was used to determine the primary and secondary organic tracers. A chemical mass balance $(\mathrm{CMB})$ model and a SOA tracer-yield model were employed to apportion the primary and secondary particulate organic matter sources. The results were compared with previous studies to explore possible emission changes of particulate matter sources in the recent years. Emission control effectiveness during the different control periods was evaluated by investigating the variations of primary and secondary particulate organic sources. The results from this study provide a baseline data set for regional air quality models to improve the understanding of the impacts of various emission controls on air quality.

\section{Experimental}

\subsection{Sampling}

A total of $12 \mathrm{~h}$ ambient $\mathrm{PM}_{2.5}$ samples were collected during the CAREBEIJING-2008 (Campaigns of Air quality REsearch in BEIJING and surrounding region) summer field campaign from 16 July to 31 August 2008, using fourchannel samplers (TH-16A, Tianhong, China) simultaneously at an urban site, located on the campus of Peking University (PKU: $39^{\circ} 59^{\prime} 21^{\prime \prime} \mathrm{N}, 116^{\circ} 18^{\prime} 25^{\prime \prime} \mathrm{E}$ ), and an upwind rural site in Yufa, located $53 \mathrm{~km}$ south of PKU $\left(39^{\circ} 30^{\prime} 49^{\prime \prime} \mathrm{N}\right.$, $\left.116^{\circ} 18^{\prime} 15^{\prime \prime} \mathrm{E}\right)$. Detailed site descriptions are reported in several previous papers (Huang et al., 2006; Guo et al., 2010; Zheng et al., 2011). Since the wind during the sampling period was mainly from the south and southwest, Yufa, located in a region dominated by farmland, was classified as an upwind rural site. The pollution concentrations at Yufa represented the regional background pollution levels (Guo et al., 2012).

During each sampling period, one Teflon filter and three quartz filters were used for particulate matter collection. There were 74 sampling periods (36 daytime periods and 38 nighttime periods) of samples obtained from PKU, and 99 sampling periods (44 daytime periods and 45 nighttime periods) of samples collected at Yufa.

\subsection{Chemical analysis}

Major water-soluble ions were ultrasonically extracted from the Teflon filters with de-ionized water and analyzed by ion chromatography (DIONEX, ICS-2500). A detailed description of this methodology can be found in a previous paper by $\mathrm{Hu}$ et al. (2005). A $1.45 \mathrm{~cm}^{2}$ area punch from each quartz filter was used to analyze elemental carbon (EC) and organic carbon (OC) by a Sunset Laboratorybased carbon analyzer (Birch and Cary, 1996). The remaining two quartz filters were ultrasonically extracted with a dichloromethane/methanol (3:1, v/v) solution and analyzed by an Agilent GC-MS system (6890 plus GC-5973N MSD) equipped with an Agilent DB-5MS GC column $(30 \mathrm{~m} \times 0.25$ $\mathrm{mm} \times 0.25 \mu \mathrm{m})$ to determine the particulate organic species. A detailed description of this analytical method has been 
reported previously (Guo et al., 2012). Briefly, 29 different internal standard compounds including ketopinic acid (KPA), 26 deuterated compounds, and 2 carbon- ${ }^{13} \mathrm{C}$-labeled compounds were spiked onto the samples, and then the filters were ultrasonically extracted with an organic solution and concentrated to $0.5-1.0 \mathrm{~mL}$. Approximately 200 $300 \mu \mathrm{L}$ of each sample extract was derivatized with BSTFA (BSTFA/TMCS, 99:1, Supelco). The derivatized and underivatized fractions were analyzed using an Agilent GC-MS system (6890 plus GC-5973N MSD). A total of 164 organic compounds were quantified. The names and the concentrations of the particulate organic species are listed in Table S1 in the Supplement. The accuracy and precision of the organic species analysis are also contained in Table S2 and S3 in the Supplement (expressed as recovery and the standard deviation of duplicate analysis).

\subsection{Source apportionment}

A chemical mass balance (EPA, version CMB 8.2) receptor model was employed to apportion the primary sources of OC. Five major primary sources were included in the model using the source profiles from the literature: vegetative detritus (Rogge et al., 1993), biomass burning (Schauer et al., 2001), coal burning (Zheng et al., 2005), non-catalyzed engines and diesel engines (Lough et al., 2007; Schauer et al., 1999, 2002). The tracers that were used in the CMB model are summarized in Table S1 in the Supplement. Because there are no well-developed source profiles for coal burning in Beijing, the source profile for coal combustion from Zheng et al. (2005) was adopted in this study. This profile was determined by the analysis of direct emissions from Datong coal burning in Yungang, China. Cholesterol, which historically was used as a tracer for Chinese cooking (Song et al., 2006b), was below the detection limit in most samples, indicating that cooking sources were not an important contributor during the study period. Additionally, due to the low concentration, the quantification of cholesterol has very large uncertainties. As a result when the cooking source profile was included, the model exhibited poor statistics, indicating unreliable results in 32 out of 74 samples at PKU and 21 out of 99 samples at Yufa (i.e., $R^{2}<0.80$ and $\chi^{2}>4$ ). Thus, cooking was excluded in the model. The small contribution from the cooking source may be also attributed to aged primary cooking particles that were transformed to SOA. If cooking or other sources not included in the model were important contributors to OC, these sources would be classified as the unapportioned OC or "other OC".

The sensitivity of the CMB model results was evaluated by verifying the input biomass burning profiles. Four biomass burning profiles were used, including one from open biomass burning (Lee et al., 2005), two from wood stoves (Fine et al., 2004; Wang et al., 2009), and one from fireplaces (Schauer et al., 2001). The contribution of biomass burning to OC varied by a factor of 0.75 to 1.33 , when different source profiles were used. Biomass burning contributions were highest when the open biomass burning profile was used. However, open biomass burning was strictly prohibited in and around Beijing during the measurement period. In addition, the contributions were very close (by a factor of 1.09) when the wood stove and fireplace source profiles were used. Other source contributions were impacted slightly (within 10\%). In this study, the fireplace profile was selected for accurate comparisons with previous work (Zheng et al., 2005). This sensitivity test demonstrated that the CMB results were reasonable and reliable.

The criteria for acceptable fitting results included the square regression coefficient of the regression equation $R^{2}$ $>0.85$, the sum of square residual chi-squared value $\chi^{2}<4$.

The contributions of secondary sources were estimated by using a tracer-yield model. In this approach, fixed ratios of tracers to OC obtained from laboratory experiments were used to determine secondary organic carbon (SOC) concentrations (Kleindienst et al., 2007). Although there are uncertainties associated with this method, this approach was useful to approximate biogenic and anthropogenic SOA from specific volatile organic compound (VOC) precursors (Kanakidou et al., 2005).

\subsection{Statistical analysis}

Typically, a direct comparison of the average values cannot determine whether two groups are statistically different. As a result, statistical analyses were used to compare data across multiple locations and time periods. A paired $t$ test was used to compare the data between two sites. To evaluate the emission control effectiveness, $F$ tests and $t$ tests were first employed to test qualitatively whether the pollution concentrations during different periods exhibited statistical differences (significance level $\alpha=5 \%, 95 \%$ confidence interval). The $F$ test was used to determine whether two groups have statistically different variances. If the two groups exhibited no statistical difference, $t$ test was used. Otherwise, $t^{\prime}$ test or variable transformation or rank-sum test was performed. In our study, all comparisons satisfied the $F$ test, so $t$ test was employed to determine whether there were statistical differences between controlled and non-controlled periods. Then the average mass concentrations of specific sources, as well as their contributions to total OC, were compared directly between different periods to determine the variation of different sources. A summary of the $t$ test statistics is listed in Table S4 in Supplement. The $t$ test results show that the primary source contributions of the four controlled periods are statistically different from those of $\mathrm{NC}$ period. Thus the average values can be used to compare directly the source contributions during the different periods. The comparison results of secondary sources varied from precursors to locations, to be discussed below. 


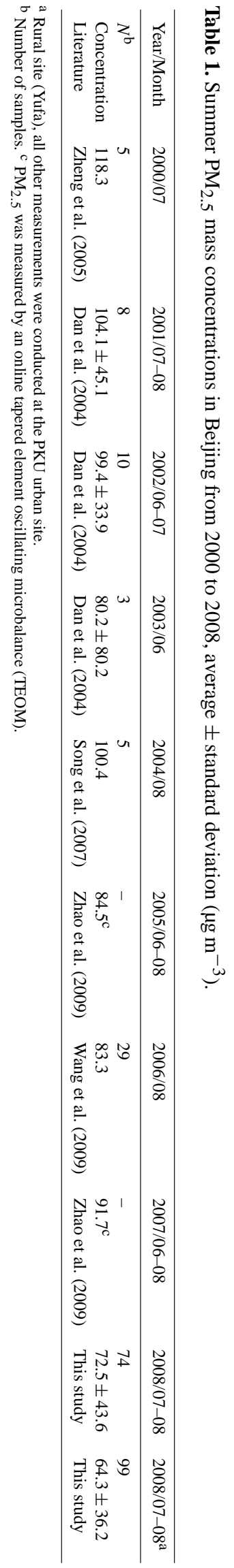




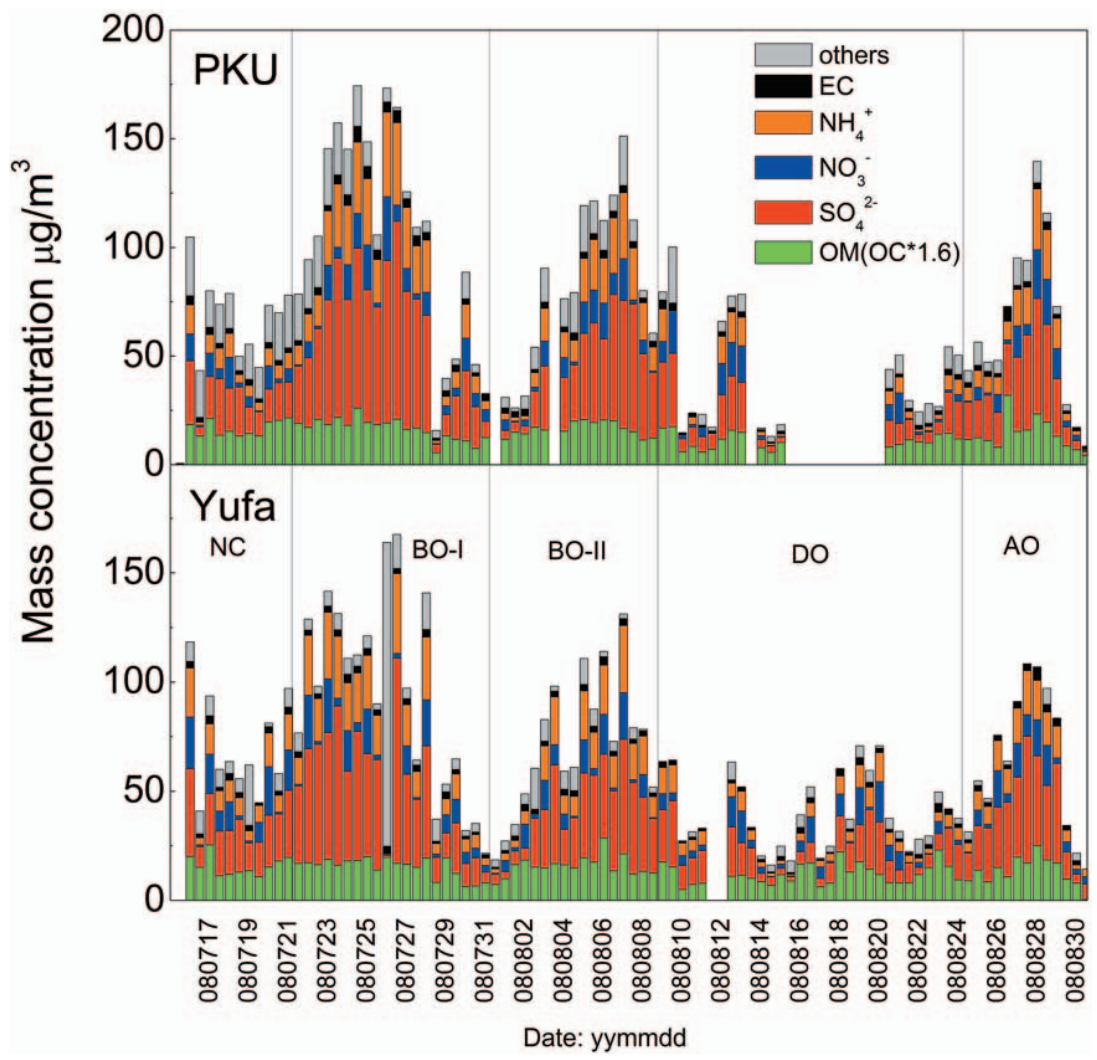

Fig. 1. $\mathrm{PM}_{2.5}$ chemical composition at the PKU urban site and the upwind Yufa rural site. Data from 16 to 20 August for the PKU site are not available for technical reasons.

Table 2. Concentration of organic carbon (OC) and elemental carbon (EC) in $\mathrm{PM}_{2.5}\left(\mu \mathrm{g} \mathrm{m}^{-3}\right)$.

\begin{tabular}{lllllll}
\hline Year/Month & $1999 / 07$ & $2000 / 07$ & $2005 / 08$ & $2006 / 08$ & $2008 / 07-08^{\mathrm{a}}$ & $2008 / 07-08^{\mathrm{b}}$ \\
\hline$N^{\mathrm{c}}$ & 12 & 5 & 46 & 43 & 74 & 99 \\
OC & 6.27 & 20.9 & 16.1 & 22.1 & $9.2 \pm 3.3$ & $8.9 \pm 3.1$ \\
EC & 9.4 & 3.0 & 5.5 & $2.6 \pm 1.3$ & $2.3 \pm 1.0$ \\
Reference & He et al. (2001) & Zheng et al. (2005) & Wang et al. (2009) & Wang et al. (2009) & This study & This study \\
\hline
\end{tabular}

a PKU site

b Yufa site

c Number of samples.

\section{Results and discussion}

\section{1 $\mathrm{PM}_{2.5}$ chemical composition of and definition of different periods}

Fine particulate mass is considered to be the most important air pollutant in Beijing during the last decade. $\mathrm{PM}_{2.5}$ mass concentrations measured during the summers of 2000 to 2008 in Beijing are shown in Table 1. Zheng et al. (2005) reported a July average $\mathrm{PM}_{2.5}$ concentration of $118.3 \mu \mathrm{g} \mathrm{m} \mathrm{m}^{-3}$ in 2000. The summer concentrations of $\mathrm{PM}_{2.5}$ gradually decreased from 2000 to 2006 (Dan et al., 2004; Song et al., 2007; Zhao et al., 2009; Wang et al., 2009). Due to unfavorable meteorological conditions, $\mathrm{PM}_{2.5}$ increased to
$91.7 \mu \mathrm{g} \mathrm{m}^{-3}$ in 2007 (Zhao et al., 2009). In this study, daily $\mathrm{PM}_{2.5}$ fluctuated drastically from 8.6 to $174.4 \mu \mathrm{g} \mathrm{m}^{-3}$ at PKU and 14.3 to $167.6 \mu \mathrm{g} \mathrm{m}^{-3}$ at Yufa. Although the fine particle pollution in Beijing decreased significantly, the concentrations were still very high compared with those in other regions of the world.

$\mathrm{PM}_{2.5}$ chemical compositions for this study period are presented in Fig. 1. Sulfate and organic particulate matter (OC*1.6) were the two most abundant components in $\mathrm{PM}_{2.5}$. Sulfate accounted for the largest fraction of the particulate matter, accounting for approximately $37 \%$ of the mass at PKU and Yufa. In total, secondary inorganic compounds (sulfate, nitrate and ammonium) represented approximately $65 \%$ of the fine mode particles at both sites, indicating that 
secondary particles were dominant during the 2008 Beijing summer. Carbonaceous materials including organic carbon (OC) and elemental carbon (EC) were also significant contributors to fine particle mass. Organic mass was the second most abundant $\mathrm{PM}_{2.5}$ component, accounting for $20 \%$ and $22 \%$ at PKU and Yufa, respectively. EC, which is produced by incomplete combustion, accounted for $4.5 \%$ and $4.0 \%$ of the $\mathrm{PM}_{2.5}$ at PKU and Yufa, respectively. A comparison of OC and EC concentrations from this study and previous work is listed in Table 2 (He et al., 2001; Zheng et al., 2005; Wang et al., 2009). The variation of OC was not significant during 2000 to 2006 . However, EC decreased significantly due to the primary emission control strategies started in 2000. In 2008 both OC and EC were the lowest measured monthly average levels over the time from 2000 and 2008 (OC 10.4 $\pm 3.8 \mu \mathrm{g} \mathrm{m}^{-3}$ at PKU and $9.4 \pm 2.1 \mu \mathrm{g} \mathrm{m}^{-3}$ at Yufa; EC $2.9 \pm 1.0 \mu \mathrm{g} \mathrm{m}^{-3}$ at PKU $2.4 \pm 0.8 \mu \mathrm{g} \mathrm{m}^{-3}$, average \pm standard deviation). These low concentrations were likely due to reductions in primary emissions as a result of drastic control measures and the favorable weather conditions during 2008 (Huang et al., 2010).

To simplify comparisons, the measurement data were divided into five periods based on the Olympic Games, control measures and weather conditions. The detailed control measures in different periods are listed in Table S5 in the Supplement. The period 15 to 20 July is defined as the "not-fullycontrolled" period (NC). The "odd-even plate number rule" for vehicles (vehicles with a license plate ending in an odd or even number can be driven on alternate days) was not implemented during this period and no precipitation occurred during this time. Two periods denoted as BO-I and BO-II were defined as "before Olympics" periods ( 21 to 31 July and 1 to 8 August) and were clearly pollution episodes. Both periods experienced stagnant weather conditions until precipitation occurred, which marked the end of these episodes. The Olympic period (DO) extended from 9 to 24 August in which several precipitation events occurred. The "odd-even plate number rule" was implemented during the BO-I, BOII and DO periods throughout the Beijing area. The "after Olympics" period (AO) extended from 25 to 31 August. During this period the "odd-even plate number rule" was only implemented in the urban area (inside the 5th Ring Road).

\subsection{Particulate organic species in different periods}

The organic compounds (not including secondary organic tracers) were cataloged into 12 classes, and their concentrations for the 5 different periods are shown in Fig.S1 in the Supplement. Detailed information for each class can be found in the Supplement (Figs. S2-S5). During the study, dicarboxylic acid was the most abundant component in all periods with the exception of the NC period at the PKU site. Previous studies have suggested that dicarboxylic acid in Beijing was mainly from secondary formation (Yao et al., 2002; Guo et al., 2010). Because the dicarboxylic acid concentrations were high, secondary formation was an important contributor to organic aerosols during the 2008 summer in Beijing. The n-alkanoic acids were the major component during the $\mathrm{NC}$ period at PKU. Although n-alkanoic acids could also be from chemical transformation, vehicle emission was determined to be the major source of this compound in Beijing (Huang et al., 2005). Thus, more traffic during the NC period may be responsible for the high n-alkanoic acid concentrations. Compared with previous work, most primary compounds such as polycyclic aromatic hydrocarbons (PAHs), hopanes and sugar compounds were much lower in 2008, as a possible result of the strict emission control measures implemented for the Olympics.

A series of $n$-alkanes ranging from $C_{12}$ to $C_{36}$ were analyzed, and their concentrations from the different periods are presented in Fig. S2 in the Supplement. The n-alkane concentrations at the two sites were highest during the NC period and lowest during the Olympics (DO period). The maximum n-alkane concentration species $\left(C_{\max }\right)$ were $\mathrm{C} 27$ and $\mathrm{C} 29$. This odd carbon preference is indicative of biogenic sources (vegetative matters and biomass burning) (Zhang et al., 2007; Rogge et al., 1993). However, low carbon number species such as C19, C20 and C21 were also high, especially at the urban site. A recent study reported that diesel and gasoline vehicles can emit large amounts of C12-C22 alkanes (Gentner et al., 2012). Results from this study suggest fossil fuel combustion and especially vehicle emissions were an important source of alkanes in Beijing.

Most PAHs are generally from a variety of combustion sources and therefore lack specificity for specific sources. It was reported that the majority of PAHs originate from anthropogenic emissions (Ravindra et al., 2008). In this study, total PAH concentrations were high in the NC period at PKU and in the $\mathrm{NC}$ and $\mathrm{AO}$ period at Yufa when traffic controls were not implemented. PAH concentrations were much lower than previous studies (Wang et al., 2009; Zheng et al., 2005). The distributions of PAHs are exhibited in the Supplement (Fig. S3). Five-ring PAHs were dominant at both sites, followed by four-ring and six-ring PAHs. Of the total PAH mass concentration, $60 \%$ and $70 \%$ consisted of the four- to sixring PAHs at PKU and Yufa, respectively. This distribution was consistent with previous work and was attributed to the volatility of PAHs and the high ambient summertime temperature (Wang et al., 2009).

Saccharide is mainly emitted from biomass burning ( $\mathrm{Si}-$ moneit, 1999). Three sugar compounds were quantified: levoglucosan, manosan and galactosan, of which levoglucosan is considered the best tracer for biomass burning. During the entire study period, levoglucosan concentrations were $97 \pm 72 \mathrm{ng} \mathrm{m}^{-3}$ and $120 \pm 78 \mathrm{ng} \mathrm{m}^{-3}$ (average \pm standard deviation) at PKU and Yufa, respectively, which was the lowest concentration in recent years. The higher levoglucosan concentration at Yufa indicates frequent biomass burning emissions in the rural area of Beijing. The highest levoglucosan concentrations were found during the $\mathrm{NC}$ period while 
Table 3. Comparison of summertime source contributions to measured $\mathrm{PM}_{2.5}$ OC in Beijing, average \pm standard deviation (\%)

\begin{tabular}{|c|c|c|c|c|c|}
\hline \multirow[t]{2}{*}{ Year/Site } & 2000 & 2005 & 2006 & 2008 & 2008 \\
\hline & PKU & PKU & PKU & PKU & Yufa \\
\hline \multirow{2}{*}{$\begin{array}{l}\text { Gasoline vehicles } \\
\text { Diesel vehicles }\end{array}$} & \multirow{2}{*}{$17.3 \pm 6.9$} & $10.6 \pm 2.8$ & $7.1 \pm 1.5$ & $10.3 \pm 8.7$ & $7.9 \pm 6.2$ \\
\hline & & $9.6 \pm 6.2$ & $5.7 \pm 1.5$ & $16.2 \pm 5.9$ & $14.5 \pm 4.1$ \\
\hline Vegetative detritus & $1.4 \pm 0.9$ & $0.3 \pm 0.2$ & $0.3 \pm 0.2$ & $1.4 \pm 0.8$ & $1.9 \pm 1.5$ \\
\hline Dust & $11.7 \pm 8.1$ & & & & \\
\hline Wood burning & $16.1 \pm 18.1$ & $10.4 \pm 3.5$ & $8.2 \pm 2.0$ & $7.5 \pm 5.5$ & $8.9 \pm 4.9$ \\
\hline Straw burning & & $1.3 \pm 0.7$ & $1.7 \pm 2.8$ & & \\
\hline Coal burning & $9.8 \pm 3.9$ & $2.1 \pm 2.2$ & $1.8 \pm 0.8$ & $5.8 \pm 5.5$ & $7.8 \pm 4.6$ \\
\hline Cigarette & $3.1 \pm 2.2$ & & & & \\
\hline Cooking & & $24.5 \pm 4.2$ & $23.8 \pm 4.3$ & & \\
\hline Isoprene SOC & & & & $9.7 \pm 5.4^{*}$ & $13.9 \pm 9.1^{*}$ \\
\hline$\alpha$-pinene SOC & & & & $5.1 \pm 2.0^{*}$ & $5.6 \pm 1.9^{*}$ \\
\hline Toluene SOC & & & & $17.4 \pm 7.6^{*}$ & $17.3 \pm 6.9^{*}$ \\
\hline$\beta$-caryophyllene SOC & & & & $2.3 \pm 1.7^{*}$ & $1.7 \pm 1.0^{*}$ \\
\hline Other $\mathrm{OC}^{*}$ & 40.6 & $41.1 \pm 9.7$ & $51.4 \pm 5.6$ & $60.7 \pm 13.2$ & $58.8 \pm 11.0$ \\
\hline Reference & Zheng et al. (2005) & Wang et & l. (2009) & This study ${ }^{*}$ & Guo et al. (2012) \\
\hline
\end{tabular}

* Other OC is unapportioned OC by CMB; SOCs were included in this portion.

the lowest concentrations were during the DO period at both sites.

Hopanes are not abundant in atmospheric particles, but can be used as indicators of vehicle emissions (Simoneit, 1986). Coal burning can also emit particulate hopanes, so the hopane concentration can also reflect the contribution of coal combustion. However, hopane concentrations from coal burning are not as high as those from vehicle emissions. In addition, coal burning is not common during summer months (Zheng et al., 2005), which reduces the likelihood of coal burning contributions. Three hopanes were measured $(17 \mathrm{~A}(\mathrm{H})-22,29,30$-trisnorhopane, $17 \mathrm{~B}(\mathrm{H})$ $21 \mathrm{~A}(\mathrm{H})-30$-norhopane, and $17 \mathrm{~A}(\mathrm{H})-21 \mathrm{~B}(\mathrm{H})$-hopane). The combined concentrations of three hopanes for five periods were $4.0 \mathrm{ng} \mathrm{m}^{-3}, 1.9 \mathrm{ng} \mathrm{m}^{-3}, 2.0 \mathrm{ng} \mathrm{m}^{-3}, 1.3 \mathrm{ng} \mathrm{m}^{-3}$, $2.0 \mathrm{ng} \mathrm{m}^{-3}$ at PKU and $2.6 \mathrm{ng} \mathrm{m}^{-3}, 2.6 \mathrm{ng} \mathrm{m}^{-3}, 2.4 \mathrm{ng} \mathrm{m}^{-3}$, $1.8 \mathrm{ng} \mathrm{m}^{-3}, 2.8 \mathrm{ng} \mathrm{m}^{-3}$ at Yufa (see Fig. S5). At PKU, hopanes were much lower during the control periods than those in the NC period. The hopane reduction at Yufa was not as significant as observed in the urban area (PKU). The hopane reduction during the controlled period suggests the implementation of traffic control did improve regional air quality. The control of coal burning may also be responsible for the hopane reduction.

Detailed discussion about SOA tracers has been reported in previous work (Guo et al., 2012). High concentrations of SOA tracers were found at both sites due to the high regional SOC background $\left(\sim 2 \mu \mathrm{g} \mathrm{C} \mathrm{m}^{-3}\right)$. Biogenic SOA tracers were higher at the rural site due to higher precursor concentrations. Anthropogenic SOA tracers were comparable between urban and rural sites, implying the anthropogenic particle pollution can influence Beijing regional air pollution.

\subsection{Source apportionment of ambient organic carbon}

Primary and secondary organic tracers were applied to a CMB model, and a tracer-yield method was used to estimate the contribution of primary and secondary particulate organic sources to total OC. Five primary sources and four secondary organic carbon compounds (SOCs) derived from isoprene, $\alpha$-pinene, $\beta$-caryophyllene and toluene were apportioned, and accounted for $73.8 \pm 9.7 \%$ (average \pm standard deviation) and $79.6 \pm 10.1 \%$ of the measured OC at PKU and Yufa, respectively. The results are listed in Table 3, and compared with results from previous source apportionment studies in Beijing (Wang et al., 2009; Zheng et al., 2005).

Vehicle emissions were a significant source of fine organic aerosols in Beijing. It was reported that the number of vehicles in Beijing has increased 20-25\% per year (China Statistical Yearbook 2011). The increase in vehicle use has led to very high fine particle pollution in Beijing (Chan and Yao, 2008). In this study, diesel and gasoline vehicle emissions were the major contributors to ambient organic particles. Diesel engines contributed $1.57 \pm 0.72 \mu \mathrm{g} \mathrm{m}^{-3}$ and $1.37 \pm 0.52 \mu \mathrm{g} \mathrm{m}^{-3}$ OC, accounting for $16.2 \pm 5.9 \%$ and $14.5 \pm 4.1 \%$ of the total organic particles (average \pm standard deviation) at the PKU and Yufa sites, respectively, while gasoline vehicles contributed $1.03 \pm 0.27 \mu \mathrm{g} \mathrm{m}^{-3}$ and $0.73 \pm 0.25 \mu \mathrm{g} \mathrm{m}^{-3}(10.3 \pm 8.7 \%$ and $7.9 \pm 6.2 \%)$. The higher contributions at PKU were reasonable because more vehicles are used in the urban area. Compared with previous studies, vehicle emissions contributed more in 2008 than in previous years. However, considering the OC concentrations, the absolute concentration attributed by vehicle emissions was lowest in 2008. The 

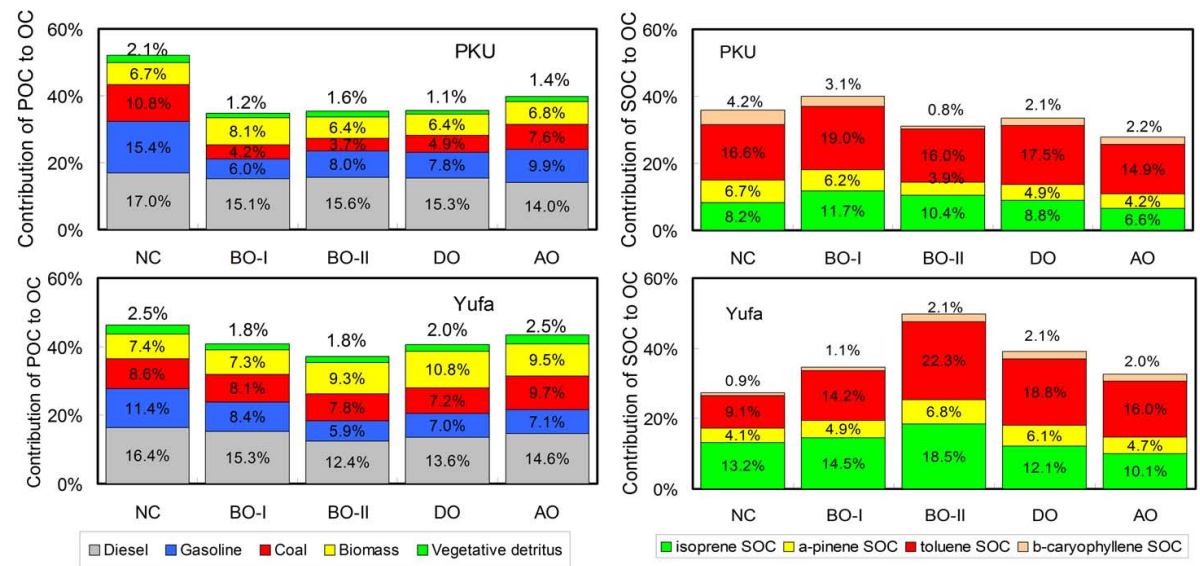

Fig. 2. Contribution of primary and secondary sources to measured $\mathrm{PM}_{2.5}$ OC during different periods. NC=not-fully-controlled, $\mathrm{BO}=$ before Olympics, $\mathrm{DO}=$ during Olympics, $\mathrm{AO}=$ after Olympics.

diesel engine contribution was reduced more significantly than gasoline engines. Gasoline vehicles were more regulated during the Olympics, whereas the volume of public transportation increased during the Olympics, which mainly used diesel engines.

Biomass burning was also an important source of ambient particles in Beijing. Open biomass burning was strictly forbidden in Beijing, and therefore its contribution to organic particles could be considered zero (Cao et al., 2005). Wood consumed as domestic fuel in the rural area contributed greatly to the ambient aerosol concentrations. In addition, the biomass burning from a nearby province may also influence Beijing air quality. In this study biomass burning contributed $7.5 \pm 5.5 \%\left(0.82 \pm 0.75 \mu \mathrm{g} \mathrm{m}^{-3}\right)$ and $8.9 \pm 4.9 \%$ $\left(0.85 \pm 0.55 \mu \mathrm{g} \mathrm{m}^{-3}\right)$ (average \pm standard deviation) of the total OC measured at PKU and Yufa. The higher contribution at Yufa was mainly due to domestic wood burning, and biomass burning aerosols contributed from a nearby province. The 2008 biomass burning contribution was lower than in 2005 and 2006.

Coal is the dominant fuel in Beijing and accounts for approximately $68.7 \%$ of the total energy production in China during 2008 (China Statistical Yearbook, 2008). In this study, coal burning accounted for $5.8 \pm 5.5 \%\left(0.66 \pm 0.59 \mu \mathrm{g} \mathrm{m}^{-3}\right)$ and $7.8 \pm 4.6 \%$ $\left(0.78 \pm 0.57 \mu \mathrm{g} \mathrm{m}^{-3}\right)$ (average \pm standard deviation) of the measured OC. This was comparable with study results in 2000, but higher than what was reported in 2005 and 2006. Because the OC concentration was much lower in 2008, the absolute coal burning OC was the lowest in recent years. The alleviation of coal burning pollution was mainly due to more strict regulation and some temporary factory closures. However, the rural area was still significantly impacted by coal combustion. Although coal cannot be used within the central urban area of Beijing, large amounts of coal were still consumed in the rural area of Beijing. In addition, the most common coal usage in the rural area was residential, which has higher emission factors (Zhang et al., 2008). Less rigorous emission control measures were also implemented in a nearby province. Rural industry and other coal usage near Beijing contributed greatly to the organic particle concentration in Beijing.

Because there were no previous studies on SOCs derived from specific VOCs, no comparison could be made to recent years. However, unapportioned OC by the CMB model was likely comprised of secondary source particles and other primary sources, like cooking emission. The CMB model could not apportion $60.0 \pm 13.2 \%$ and $59.0 \pm 11.0 \%$ of the OC from PKU and Yufa, respectively.

\subsection{Variation of organic particle sources in different periods}

In order to improve air quality for the Olympic Games, the Beijing Municipal Government implemented a series of measures to alleviate particulate matter pollution. This provided a good opportunity to understand the impact of reduced emissions on air pollution. The OC concentrations from major primary and secondary sources and their contributions to total ambient organic carbon are shown in Fig. 2 and Table 4. Statistical analyses were conducted to evaluate the emission control effectiveness, and the statistical results are shown in Table S4 in the Supplement.

Vehicles were rigorously controlled as an emission source during the Olympics. The detailed control measures are listed in Table S5 in the Supplement. At the urban site (PKU), vehicle emissions were the major source of organic particles during the NC period. Vehicle contributions decreased considerably during the next four controlled periods. The $t$ test result showed the OC concentration attributed by vehicles in the NC period was significantly higher than those in the controlled periods. The OC concentrations from gasoline vehicles during the controlled periods decreased by $54 \%$ 
Table 4. Organic carbon contributions from major primary and secondary sources during different periods $\left(\mu \mathrm{g} \mathrm{m}^{-3}\right)$.

\begin{tabular}{l|lllll|lllll}
\hline & NC & BO-I & BO-II & DO & AO & NC & BO-I & BO-II & DO & AO \\
\hline & PKU & & & & & Yufa & & & & \\
\cline { 2 - 10 } & 0.82 & 1.26 & 1.04 & 0.67 & 0.57 & 1.42 & 1.46 & 1.86 & 1.00 & 0.95 \\
Isoprene SOC & 0.67 & 0.67 & 0.39 & 0.38 & 0.36 & 0.45 & 0.49 & 0.69 & 0.50 & 0.44 \\
-pinene SOC & 1.66 & 2.05 & 1.61 & 1.34 & 1.29 & 0.99 & 1.43 & 2.24 & 1.55 & 1.52 \\
Toluene SOC & 0.42 & 0.33 & 0.08 & 0.16 & 0.19 & 0.09 & 0.11 & 0.21 & 0.18 & 0.19 \\
$\beta$-caryophyllene SOC & 0.21 & 0.13 & 0.16 & 0.08 & 0.12 & 0.27 & 0.18 & 0.18 & 0.16 & 0.24 \\
Vegetative detritus & 0.67 & 0.87 & 0.65 & 0.49 & 0.59 & 0.79 & 0.73 & 0.93 & 0.89 & 0.90 \\
Biomass burning & 1.69 & 1.63 & 1.57 & 1.17 & 1.22 & 1.76 & 1.54 & 1.25 & 1.12 & 1.38 \\
Diesel vehicles & 1.54 & 0.65 & 0.81 & 0.59 & 0.86 & 1.23 & 0.84 & 0.60 & 0.57 & 0.67 \\
Gasoline vehicles & 1.08 & 0.46 & 0.37 & 0.38 & 0.66 & 0.92 & 0.82 & 0.78 & 0.59 & 0.92 \\
Coal burning & 1.21 & 2.72 & 3.38 & 2.37 & 2.82 & 2.84 & 2.45 & 1.32 & 1.67 & 2.26 \\
Other OC & & &
\end{tabular}

Note: $\mathrm{NC}=$ not-fully-controlled, $\mathrm{BO}=$ before Olympics, $\mathrm{DO}=$ during Olympics, $\mathrm{AO}=$ after Olympics .

compared with the NC period. The average OC concentrations from diesel vehicles decreased by $13 \%$ during the control periods. However, the reduction of absolute concentrations can be influenced by weather conditions, so these results cannot be used to evaluate the control measure effectiveness. Therefore, understanding the variations of source contributions (percent of specific sources to total OC) is a better way to assess the impact of these emission control measures. Comparing the NC period with the whole control period, there was a $52 \%$ average reduction of gasoline vehicle contributions. Correspondingly, the diesel vehicle OC contributions were reduced by $11 \%$. The average OC contribution from vehicle emissions was reduced by $30 \%$. Although the official traffic reduction estimate was approximately $60 \%$, there were no accurate data of vehicle use. However, the result from this study was consistent with the estimated total $\mathrm{PM}_{2.5}$ reduction using a statistical model from Liu et al. (2012).

Coal combustion OC also decreased during the four control periods with an average reduction of $59 \%$ and $57 \%$ in concentration and the relative contribution to particulate matter, respectively. The contributions of biomass burning showed statistical differences between NC period and BOI, BO-II, DO and AO periods (see Table S4), suggesting biomass burning was also well controlled. Results indicate the control measures significantly improved Beijing's urban air quality.

Since Yufa was an upwind rural and regional site, the variation of source contributions at Yufa can evaluate the emission control effectiveness on a regional scale. Vehicle emissions were the major source of organic particles at Yufa, which decreased during the control periods. Although the reduction was not as significant as at PKU, the contributions of gasoline vehicle emissions decreased by $39 \%$ and $14 \%$ for diesel vehicles at Yufa. The combined contribution from two kinds of vehicle emission was reduced at Yufa by $24 \%$. Table S4 in the Supplement indicates that the biomass burning contributions in NC period were statistically different from the controlled period. The biomass burning was also well controlled at Yufa. Particle pollution from coal burning was reduced by $17 \%$ in concentration and $7 \%$ in the relative OC contribution. The reduction of coal burning emission in Yufa was not as significant as that in the urban area. This may be due to emission influences from neighboring provinces. Nevertheless, the control measures greatly reduced the regional primary organic particle pollution.

Secondary aerosol formation processes including nucleation, gas-to-particle transformation and multiphase reactions are poorly understood (Zhang et al., 2012; Hallquist et al., 2009; Zhang, 2010). Secondary organic aerosol (SOA) formation is very complicated, and can be affected by many factors such as precursors, ambient temperature, humidity, and particle acidity (Wang et al., 2010a, b; Zhao et al., 2006; Saathoff et al., 2009). In this study, SOCs derived from isoprene, $\alpha$-pinene, $\beta$-caryophyllene and toluene were apportioned, and their concentrations and contributions to the measured OC in different periods are presented in Table 4 and Fig. 2. Three major SOCs from toluene, isoprene and $\alpha$ pinene showed similar trends at the PKU and Yufa sites. The highest SOC concentrations were observed during the BO-I period at PKU and BO-II period at Yufa when weather conditions were favorable for SOA formation and accumulation (high radiation, temperature, humidity, $\mathrm{O}_{3}$ concentration and no precipitation).

At the urban site (PKU), the anthropogenic SOC contributions did not have any statistical differences between the controlled and NC periods (Table S4 in the Supplement). However, the biogenic SOC contributions, such as isoprene SOC, had a statistical difference, with an increase of $8 \%$ during the controlled period. From this study data, the reduction of SOA is not observed. At the rural site (Yufa), both biogenic and anthropogenic SOCs were higher in the controlled period. More advanced techniques and modeling studies are 
needed to evaluate the impact of emission controls on SOA formation more completely.

\section{Conclusion}

On the basis of a quantitative evaluation of emission controls on primary and secondary organic aerosol sources during the 2008 Beijing Olympic Games, we conclude that $\mathrm{PM}_{2.5}$ and carbonaceous components were at their lowest levels in recent years. The improvement of air quality was mainly due to the drastic emission control measures and favorable weather conditions. Five major primary sources and four SOCs were identified by the CMB model and the tracer-yield method. Compared with previous source apportionment work, vehicle emission has become the major source of organic particles, on both the urban and the regional scale. Due to the emission control measures, the absolute concentrations from vehicles were gradually reduced, especially in 2008 when more strict measures were implemented. For the same reason, both coal combustion and biomass burning OC decreased, and OC was at its lowest during 2008 compared to previous years. Organic particles transported from nearby provinces also contributed to organic particles in the rural area of Beijing. Secondary formation became a significant contributor to ambient fine organic particles in Beijing. Nevertheless, the absolute SOC concentrations also decreased compared with those in previous years.

Vehicle contributions were reduced by $30 \%$ in the urban area and by $24 \%$ on a regional scale. The contribution from coal combustion was also reduced by $57 \%$ and $7 \%$ at the urban and the regional scale, respectively. Our results suggest the emission control measures significantly alleviated the organic particle pollution in and around Beijing. More studies are needed to evaluate the impact of the emission controls on SOA formation. Because weather conditions represented a major factor influencing SOC formation, reducing precursor and oxidant concentrations may be a viable means to reduce secondary particle pollution. To improve the regional air quality, especially reducing secondary particle pollution, more strict control measures should be implemented on a larger regional scale in the future.

\section{Supplementary material related to this article is available online at: http://www.atmos-chem-phys.net/13/ 8303/2013/acp-13-8303-2013-supplement.pdf.}

Acknowledgements. This work was supported by the National Natural Science Foundation of China (21025728), National Basic Research Program, China Ministry of Science and Technology (2013CB228503), the National Natural Science Foundation of China (21190052, 41121004), and the China Ministry of Environmental Protection's Special Funds for Scientific Research on Public
Welfare (201009002). The authors also would like to thank Misti Levy for editing of the manuscript.

Edited by: L. M. Russell

\section{References}

Birch, M. E. and Cary, R. A.: Elemental carbon-based method for monitoring occupational exposures to particulate diesel exhaust, Aerosol Sci. Technol., 25, 221-241, doi:10.1080/02786829608965393, 1996.

Cao, G., Zhang, X., Wang, D., and Zheng, F.: Inventory of emissions of pollutants from open burning crop residue, J. Agr. Environ. Sci., 24, 800-804, 2005.

Cermak, J. and Knutti, R.: Beijing Olympics as an aerosol field experiment, Geophys. Res. Lett., 36, L10806, doi:10.1029/2009GL038572, 2009.

Chan, C. K., and Yao, X.: Air pollution in mega cities in China, Atmos. Environ., 42, 1-42, doi:10.1016/j.atmosenv.2007.09.003, 2008.

Dan, M., Zhuang, G. S., Li, X. X., Tao, H. R., and Zhuang, Y. H.: The characteristics of carbonaceous species and their sources in $\mathrm{PM}_{2.5}$ in Beijing, Atmos. Environ., 38, 3443-3452, doi:10.1016/j.atmosenv.2004.02.052, 2004.

Fine, P. M., Cass, G. R., and Simoneit, B. R. T.: Chemical characterization of fine particle emissions from the fireplace combustion of wood types grown in the Midwestern and Western United States, Environ. Eng. Sci., 21, 387-409, 2004.

Gentner, D. R., Isaacman, G., Worton, D. R., Chan, A. W. H., Dallmann, T. R., Davis, L., Liu, S., Day, D. A., Russell, L. M., Wilson, K. R., Weber, R., Guha, A., Harley, R. A., and Goldstein, A. H.: Elucidating secondary organic aerosol from diesel and gasoline vehicles through detailed characterization of organic carbon emissions, Prog. Natl. Acad. Sci. USA, 109, 18318-18323, 2012.

Guo, S., Hu, M., Wang, Z. B., Slanina, J., and Zhao, Y. L.: Sizeresolved aerosol water-soluble ionic compositions in the summer of Beijing: implication of regional secondary formation, Atmos. Chem. Phys., 10, 947-959, doi:10.5194/acp-10-947-2010, 2010.

Guo, S., Hu, M., Guo, Q., Zhang, X., Zheng, M., Zheng, J., Chang, C.-C., Schauer, J. J., and Zhang, R.: Primary Sources and Secondary Formation of Organic Aerosols in Beijing, China, Environ. Sci. Technol., 46, 9846-9853, doi:10.1021/es2042564, 2012.

Hallquist, M., Wenger, J. C., Baltensperger, U., Rudich, Y., Simpson, D., Claeys, M., Dommen, J., Donahue, N. M., George, C., Goldstein, A. H., Hamilton, J. F., Herrmann, H., Hoffmann, T., Iinuma, Y., Jang, M., Jenkin, M. E., Jimenez, J. L., Kiendler-Scharr, A., Maenhaut, W., McFiggans, G., Mentel, Th. F., Monod, A., Prévôt, A. S. H., Seinfeld, J. H., Surratt, J. D., Szmigielski, R., and Wildt, J.: The formation, properties and impact of secondary organic aerosol: current and emerging issues, Atmos. Chem. Phys., 9, 5155-5236, doi:10.5194/acp-9-51552009, 2009.

He, K. B., Yang, F. M., Ma, Y. L., Zhang, Q., Yao, X. H., Chan, C. K., Cadle, S., Chan, T., and Mulawa, P.: The characteristics of $\mathrm{PM}_{2.5}$ in Beijing, China, Atmos. Environ., 35, 4959-4970, 2001.

$\mathrm{Hu}$, M., Zhang, J., and Wu, Z. J.: Chemical compositions of precipitation and scavenging of particles in Beijing, Sci. China Ser. B, 48, 265-272, doi:10.1360/042004-49, 2005. 
$\mathrm{Hu}$, M. and Guo, S.: Particle pollution in Beijing: features, source and secondary formation, IGAC Newsletter, 42, 10-18, 2009.

Huang, X. F., Hu, M., He, L. Y., and Tang, X. Y.: Chemical characterization of water-soluble organic acids in $\mathrm{PM}_{2.5}$ in Beijing, China, Atmos. Environ., 39, 2819-2827, doi:10.1016/j.atmosenv.2004.08.038, 2005.

Huang, X. F., He, L. Y., Hu, M., and Zhang, Y. H.: Annual variation of particulate organic compounds in $\mathrm{PM}_{2.5}$ in the urban atmosphere of Beijing, Atmos. Environ., 40, 2449-2458, doi:10.1016/j.atmosenv.2005.12.039, 2006.

Huang, X. F., He, L. Y., Hu, M., Canagaratna, M. R., Sun, Y., Zhang, Q., Zhu, T., Xue, L., Zeng, L. W., Liu, X. G., Zhang, Y. H., Jayne, J. T., Ng, N. L., and Worsnop, D. R.: Highly time-resolved chemical characterization of atmospheric submicron particles during 2008 Beijing Olympic Games using an Aerodyne HighResolution Aerosol Mass Spectrometer, Atmos. Chem. Phys., 10, 8933-8945, doi:10.5194/acp-10-8933-2010, 2010.

Kanakidou, M., Seinfeld, J. H., Pandis, S. N., Barnes, I., Dentener, F. J., Facchini, M. C., Van Dingenen, R., Ervens, B., Nenes, A., Nielsen, C. J., Swietlicki, E., Putaud, J. P., Balkanski, Y., Fuzzi, S., Horth, J., Moortgat, G. K., Winterhalter, R., Myhre, C. E. L., Tsigaridis, K., Vignati, E., Stephanou, E. G., and Wilson, J.: Organic aerosol and global climate modelling: a review, Atmos. Chem. Phys., 5, 1053-1123, doi:10.5194/acp-5-1053-2005, 2005.

Kleindienst, T. E., Jaoui, M., Lewandowski, M., Offenberg, J. H., Lewis, C. W., Bhave, P. V., and Edney, E. O.: Estimates of the contributions of biogenic and anthropogenic hydrocarbons to secondary organic aerosol at a southeastern US location, Atmos. Environ., 41, 8288-8300, doi:10.1016/j.atmosenv.2007.06.045, 2007.

Lee, S., Baumann, K., Schauer, J. J., Sheesley, R. J., Naeher, L. P., Meinardi, S., Blake, D. R., Edgerton, E. S., Russell, A. G., and Clements, M.: Gaseous and particulate emissions from prescribed burning in Georgia, Environ. Sci. Technol., 39, 90499056, 2005.

Lin, P., Hu, M., Deng, Z., Slanina, J., Han, S., Kondo, Y., Takegawa, N., Miyazaki, Y., Zhao, Y., and Sugimoto, N.: Seasonal and diurnal variations of organic carbon in $\mathrm{PM}_{2.5}$ in Beijing and the estimation of secondary organic carbon, J. Geophys. Res.-Atmos., 114, D00G11, doi:10.1029/2008JD010902, 2009.

Liu, Y., He, K. B., Li, S. S., Wang, Z. X., Christiani, D. C., and Koutrakis, P.: A statistical model to evaluate the effectiveness of $\mathrm{PM}_{2.5}$ emissions control during the Beijing 2008 Olympic Games, Environ. Int., 44, 100-105, doi:10.1016/j.envint.2012.02.003, 2012.

Lough, G. C., Christensen, C. G., Schauer, J. J., Tortorelli, J., Mani, E., Lawson, D. R., Clark, N. N., and Gabele, P. A.: Development of molecular marker source profiles for emissions from onroad gasoline and diesel vehicle fleets, J. Air Waste Manage., 57, 1190-1199, doi:10.3155/1047-3289.57.10.1190, 2007.

Ravindra, K., Sokhi, R., and Van Grieken, R.: Atmospheric polycyclic aromatic hydrocarbons: Source attribution, emission factors and regulation, Atmos. Environ., 42, 2895-2921, doi:10.1016/j.atmosenv.2007.12.010, 2008.

Rogge, W. F., Hildemann, L. M., Mazurek, M. A., Cass, G. R., and Simoneit, B. R. T.: Sources of Fine Organic Aerosol.4. Particulate Abrasion Products from Leaf Surfaces of Urban Plants, Environ. Sci. Technol., 27, 2700-2711, 1993.
Saathoff, H., Naumann, K.-H., Möhler, O., Jonsson, Å. M., Hallquist, M., Kiendler-Scharr, A., Mentel, Th. F., Tillmann, R., and Schurath, U.: Temperature dependence of yields of secondary organic aerosols from the ozonolysis of $\alpha$-pinene and limonene, Atmos. Chem. Phys., 9, 1551-1577, doi:10.5194/acp-9-15512009, 2009.

Schauer, J. J., Rogge, W. F., Hildemann, L. M., Mazurek, M. A., and Cass, G. R.: Source apportionment of airborne particulate matter using organic compounds as tracers, Atmos. Environ., 30, 3837-855, 1996.

Schauer, J. J., Kleeman, M. J., Cass, G. R., and Simoneit, B. R. T.: Measurement of emissions from air pollution sources. 2. C1 through C-30 organic compounds from medium duty diesel trucks, Environ. Sci. Technol., 33, 1578-1587, 1999.

Schauer, J. J., Kleeman, M. J., Cass, G. R., and Simoneit, B. R. T.: Measurement of emissions from air pollution sources. 3. C1-C-29 organic compounds from fireplace combustion of wood, Environ. Sci. Technol., 35, 1716-1728, 2001.

Schauer, J. J., Kleeman, M. J., Cass, G. R., and Simoneit, B. R. T.: Measurement of emissions from air pollution sources. 5. C-1-C32 organic compounds from gasoline-powered motor vehicles, Environ. Sci. Technol., 36, 1169-1180, doi:10.1021/Es0108077, 2002.

Shao, M., Tang, X. Y., Zhang, Y. H., and Li, W. J.: City clusters in China: air and surface water pollution, Front Ecol. Environ, 4, 353-361, 2006.

Simoneit, B. R. T.: Characterization of Organic-Constituents in Aerosols in Relation to Their Origin and Transport - a Review, Int. J. Environ. , 23, 207-237, 1986.

Simoneit, B. R. T.: A review of biomarker compounds as source indicators and tracers for air pollution, Environ. Sci. Pollut. R., 6, 159-169, 1999

Song, Y., Zhang, Y. H., Xie, S. D., Zeng, L. M., Zheng, M., Salmon, L. G., Shao, M., and Slanina, S.: Source apportionment of $\mathrm{PM}_{2.5}$ in Beijing by positive matrix factorization, Atmos. Environ., 40, 1526-1537, doi:10.1016/j.atmosenv.2005.10.039, 2006a.

Song, Y., Zhang, Y. H., Xie, S. D., Zeng, L. M., Zheng, M., Salmon, L. G., Shao, M., and Slanina, S.: Source apportionment of $\mathrm{PM}_{2.5}$ in Beijing by positive matrix factorization (vol 40, pg 1526, 2006), Atmos. Environ., 40, 7661-7662, doi:10.1016/j.atmosenv.2006.09.006, 2006b.

Song, Y., Tang, X. Y., Xie, S. D., Zhang, Y. H., Wei, Y. J., Zhang, M. S., Zeng, L. M., and Lu, S. H.: Source apportionment of $\mathrm{PM}_{2.5}$ in Beijing in 2004, J. Hazard. Mater., 146, 124-130, doi:10.1016/j.jhazmat.2006.11.058, 2007.

Stone, E. A., Zhou, J. B., Snyder, D. C., Rutter, A. P., Mieritz, M., and Schauer, J. J.: A Comparison of Summertime Secondary Organic Aerosol Source Contributions at Contrasting Urban Locations, Environ. Sci. Technol., 43, 3448-3454, doi:10.1021/Es8025209, 2009.

Sun, X. S., Hu, M., Guo, S., Liu, K. X., and Zhou, L. P.: C-14-Based source assessment of carbonaceous aerosols at a rural site, Atmos. Environ., 50, 36-40, doi:10.1016/j.atmosenv.2012.01.008, 2012.

Sun, Y., Zhuang, G. S., Zhang, W. J., Wang, Y., and Zhuang, Y. H.: Characteristics and sources of lead pollution after phasing out leaded gasoline in Beijing, Atmos. Environ., 40, 2973-2985, doi:10.1016/j.atmosenv.2005.12.032, 2006. 
Wang, L., Khalizov, A. F., Zheng, J., Xu, W., Ma, Y., Lal, V., and Zhang, R. Y.: Atmospheric nanoparticles formed from heterogeneous reactions of organics, Nat. Geosci., 3, 238-242, doi:10.1038/Ngeo778, 2010a.

Wang, L., Lal, V., Khalizov, A. F., and Zhang, R. Y.: Heterogeneous Chemistry of Alkylamines with Sulfuric Acid: Implications for Atmospheric Formation of Alkylaminium Sulfates, Environ. Sci. Technol., 44, 2461-2465, doi:10.1021/Es9036868, 2010b.

Wang, Q., Shao, M., Zhang, Y., Wei, Y., Hu, M., and Guo, S.: Source apportionment of fine organic aerosols in Beijing, Atmos. Chem. Phys., 9, 8573-8585, doi:10.5194/acp-9-8573-2009, 2009.

Wang, S. X., Zhao, M., Xing, J., Wu, Y., Zhou, Y., Lei, Y., He, K. B., Fu, L. X., and Hao, J. M.: Quantifying the Air Pollutants Emission Reduction during the 2008 Olympic Games in Beijing, Environ. Sci. Technol., 44, 2490-2496, doi:10.1021/Es9028167, 2010c.

Yao, X. H., Fang, M., and Chan, C. K.: Size distributions and formation of dicarboxylic acids in atmospheric particles, Atmos. Environ., 36, 2099-2107, 2002.

Zhang, R. Y.: Getting to the Critical Nucleus of Aerosol Formation, Science, 328, 1366-1367, doi:10.1126/science.1189732, 2010.

Zhang, R. Y., Khalizov, A., Wang, L., Hu, M., and Xu, W.: Nucleation and Growth of Nanoparticles in the Atmosphere, Chem. Rev., 112, 1957-2011, doi:10.1021/Cr2001756, 2012.

Zhang, Y. X., Shao, M., Zhang, Y. H., Zeng, L. M., He, L. Y., Zhu, B., Wei, Y. J., and Zhu, X. L.: Source profiles of particulate organic matters emitted from cereal straw burnings, J. Environ. Sci.-China, 19, 167-175, 2007.
Zhang, Y. X., Schauer, J. J., Zhang, Y. H., Zeng, L. M., Wei, Y. J., Liu, Y., and Shao, M.: Characteristics of particulate carbon emissions from real-world Chinese coal combustion, Environ. Sci. Technol., 42, 5068-5073, doi:10.1021/Es7022576, 2008.

Zhao, J., Levitt, N. P., Zhang, R. Y., and Chen, J. M.: Heterogeneous reactions of methylglyoxal in acidic media: Implications for secondary organic aerosol formation, Environ. Sci. Technol., 40, 7682-7687, doi:10.1021/Es060610k, 2006.

Zhao, X. J., Zhang, X. L., Xu, X. F., Xu, J., Meng, W., and Pu, W. W.: Seasonal and diurnal variations of ambient $\mathrm{PM}_{2.5}$ concentration in urban and rural environments in Beijing, Atmos. Environ., 43, 2893-2900, doi:10.1016/j.atmosenv.2009.03.009, 2009.

Zheng, J., Hu, M., Zhang, R., Yue, D., Wang, Z., Guo, S., Li, X., Bohn, B., Shao, M., He, L., Huang, X., Wiedensohler, A., and Zhu, T.: Measurements of gaseous $\mathrm{H}_{2} \mathrm{SO}_{4}$ by AP-ID-CIMS during CAREBeijing 2008 Campaign, Atmos. Chem. Phys., 11, 7755-7765, doi:10.5194/acp-11-7755-2011, 2011.

Zheng, M., Salmon, L. G., Schauer, J. J., Zeng, L. M., Kiang, C. S., Zhang, Y. H., and Cass, G. R.: Seasonal trends in $\mathrm{PM}_{2.5}$ source contributions in Beijing, China, Atmos. Environ., 39, 3967-3976, doi:10.1016/j.atmosenv.2005.03.036, 2005. 